\title{
内蒙古民族地区中学化学校本课程开发研究
}

\author{
张莹陈丽萍
}

内蒙古师范大学化学与环境科学学院

DOI:10.32629/er.v2i11.2148

[摘 要] 化学校本课程为化学教学提供良好平台, 本研究立足内蒙古民族地区, 通过对蒙古族聚居地区校本课程开发的现状分析, 阐述校本课程 开发的问题,并提供开发的基本思路,给出了蒙古族地区校本课程开发的具体案例,为国内少数民族地区的校本课程开发提供借鉴。

[关键词] 蒙古族地区; 中学化学; 校本课程; 开发

自我国实行课程三级管理制度以来, 涌现了大批对沿海省份校本课程 的相关研究, 虽有利于校本课程在我国的开发、实施与推广, 但并未对少数 民族地区的校本课程给予足够关注, 有关蒙古族地区学科校本课程开发的 研究少之又少, 因此该地区中学化学校本课程的开发需要深入研究 ${ }^{[1]}$ 。长 期以来, 蒙古族地区的化学教学质量与沿海地区差距较大, 本次研究以期 借助特色校本课程提高蒙古族学生的积极性, 提升学习效率。内蒙古乌海 市丰富的民族文化背景决定了校本课程开发的独特性, 蒙古族地区校本课 程的开发应以《普通高中化学课程标准 (2017年版)》(以下简称新课标) 规定的课程目标为标准 ${ }^{[2]}$, 以当地学生发展为基准点和归宿, 结合学校和 民族特色选取教学内容, 开发内蒙古民族地区中学化学校本课程。

\section{1 现状调查研究}

1. 1 开发背景

乌海市蒙古族人较多, 风俗习惯、语言等因素促进化学学科的教学, 也在一定程度上阻碍其发展。乌海市R中学的化学教学质量在内蒙古地区 相对较好, 但因其偏僻的地理位置、对教育新理念理解偏差等原因, 整体落 后于沿海地区。另外因蒙古族多以放牧为生, 该地区的学生无论自身学习 动机或是学业成就感、社会竞争压力等都与其他地区学生有差距, 自身基 础薄弱, 又不能很好的认识自己, 缺乏学习的明确动力; 而且该地区的现用 教材与其他地方相统一, 学生在课程难度大、进度快的时候容易产生庈倦 心理, 难以适应当地学生的需求与发展。

1. 2 现状调查

表1 学生问卷调查统计表

\begin{tabular}{|c|c|c|c|}
\hline 题目 & 选项 & 选择人数 & 比例 \\
\hline \multirow{2}{*}{ 性别 } & 男 & 161 & $52.4 \%$ \\
\hline & 女 & 146 & $47.6 \%$ \\
\hline \multirow{3}{*}{ 对高中化学的学习兴趣 } & 感兴趣 & 121 & $39.4 \%$ \\
\hline & 一般 & 68 & $22.1 \%$ \\
\hline & 不感兴趣 & 118 & $38.5 \%$ \\
\hline \multirow{4}{*}{ 是否满意现在的化学学习状态 } & 很满意 & 33 & $10.7 \%$ \\
\hline & 比较满意 & 79 & $25.7 \%$ \\
\hline & 不太满意 & 127 & $41.4 \%$ \\
\hline & 非常不满意 & 68 & $22.1 \%$ \\
\hline \multirow{4}{*}{$\begin{array}{c}\text { 导致自己目前学习状态的主要 } \\
\text { 原因 }\end{array}$} & 学习基础 & 43 & $14.0 \%$ \\
\hline & 课程难度 & 39 & $12.8 \%$ \\
\hline & 兴趣 & 161 & $52.4 \%$ \\
\hline & 教师教学方式 & 64 & $20.8 \%$ \\
\hline \multirow{4}{*}{$\begin{array}{c}\text { 对学校开发适合自己的高中化 } \\
\text { 学校本课程的期望 }\end{array}$} & 非常希望 & 129 & $42.0 \%$ \\
\hline & 希望 & 150 & $48.9 \%$ \\
\hline & 不希望 & 23 & $7.5 \%$ \\
\hline & 无所谓 & 5 & $1.6 \%$ \\
\hline \multirow{4}{*}{$\begin{array}{c}\text { 对自己目前在化学学习中最欠 } \\
\text { 缺部分的看法 }\end{array}$} & 学习基础 & 166 & $54.1 \%$ \\
\hline & 学习兴趣 & 56 & $18.2 \%$ \\
\hline & 学习方法 & 74 & $24.1 \%$ \\
\hline & 其他 & 11 & $3.6 \%$ \\
\hline
\end{tabular}

2018年9-12月, 本研究利用问卷调查法对R中学的 10 名化学教师及 310 名学生 (收回 307份) 分别就蒙古族地区中学化学校本课程的开发现状、学 生需求、教学方式、课程的结构和目标要求等情况做了调查, 对调查结果 统计分析。

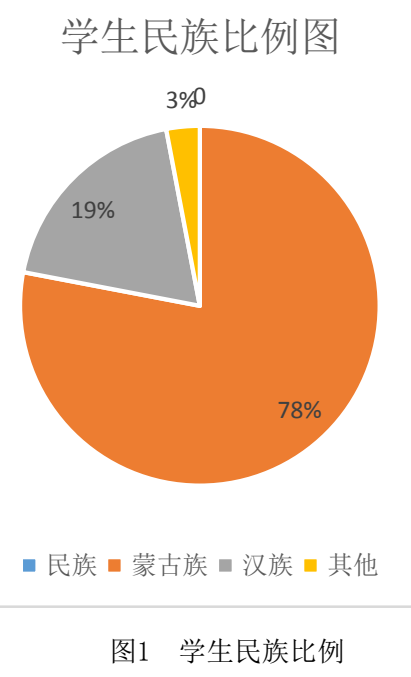

分析发现, R中学蒙古族学生占比极高, 如图 1, 较多学生对化学的学习 热情不高, 同时学生对自己目前的学习状态也不满意, 总结原因部分学生 认为是兴趣的缺失和教学方法老套导致, 大部分人认为是由于现行教材难 度较大, 学习过程中学生自身难以解决的问题较多, 学生几乎一致希望学 校可以安排适合自己的学习课程, 让化学成绩得到提升。可见学生的实际 需求如此迫切, 再加上政策上的支持, 开发真正适合学生的化学校本课程 迫在眉睫。

分析得, R中学的化学教师较年轻, 以青年教师为主, 熟知目前的教育 形势, 教学经验丰富; 大部分教师为本科及以上学历, 具备课程开发的人力 智力基础; 虽然教师还需进一步加深对校本课程的认识, 但还是普遍认为 现行的高中教材与当地学生紧密度不够, 有必要开发适合蒙古族学生的校 本课程。综上, 通过对教师的调查我们了解到校本课程的开发在主观和客 观上均具备有利条件。

1. 3现有问题

经分析, 蒙古族地区校本课程的现有问题主要集中在以下几个方面:

1.3. 1课程专家或专业人士的指导不足

长期以来教育界对课程的忽视导致我国的课程专家少之又少, 蒙古族 课程专家更是塞塞无几, 蒙古族地区课程开发情况复杂, 因此急需课程专 家或专业人士的指导。如鄂托克前旗开展的 “马文化节” 校本课程受到了 教师、学生及家长的大力支持, 也有内蒙古民俗专家的参与, 但由于缺少学 
科型课程专家在理论与实践方面的指导, 即使课程的设置再成功也仅停留 在传承少数民族传统文化为归宿的层次, 并没有完备的校本课程开发纲要 和实施计划, 未将校本课程规范化和系统化。

\begin{tabular}{|c|c|c|c|}
\hline 题目 & 选项 & 选择人数 & 比例 \\
\hline \multirow{2}{*}{ 性别 } & 男 & 3 & $30 \%$ \\
\hline & 女 & 7 & $70 \%$ \\
\hline \multirow{4}{*}{ 年龄 } & 30 岁以下 & 1 & $10 \%$ \\
\hline & $30-40$ & 4 & $40 \%$ \\
\hline & $40-50$ & 3 & $30 \%$ \\
\hline & 50 岁以上 & 2 & $20 \%$ \\
\hline \multirow{3}{*}{ 职称 } & 初级 & 2 & $20 \%$ \\
\hline & 中级 & 5 & $50 \%$ \\
\hline & 高级 & 3 & $30 \%$ \\
\hline \multirow{3}{*}{ 学历 } & 大专 & 2 & $20 \%$ \\
\hline & 大学本科 & 6 & $40 \%$ \\
\hline & 硕士研究生 & 2 & $20 \%$ \\
\hline \multirow{3}{*}{ 是否了解化学校本课程 } & 不了解 & 0 & 0 \\
\hline & 基本了解 & 8 & $80 \%$ \\
\hline & 非常了解 & 2 & $20 \%$ \\
\hline \multirow{4}{*}{ 对校本课程的理解 } & 学校或教师自编教材而实施的课程 & 2 & $20 \%$ \\
\hline & 活动课程或选修课程 & 1 & $10 \%$ \\
\hline & 根据学生和地区的实际需要而开发的课程 & 7 & $70 \%$ \\
\hline & 教育部按照国家要求安排的工作 & 0 & 0 \\
\hline \multirow{4}{*}{ 是否满意现行高中教材 } & $\begin{array}{c}\text { 很满意 } \\
\end{array}$ & 1 & $10 \%$ \\
\hline & 比较满意 & 4 & $40 \%$ \\
\hline & 不太满意 & 4 & $40 \%$ \\
\hline & 很不满意 & 1 & $10 \%$ \\
\hline \multirow{4}{*}{$\begin{array}{c}\text { 现行的化学课程对蒙古 } \\
\text { 族学生是否适合 }\end{array}$} & 很合适 & 1 & $10 \%$ \\
\hline & 不太合适 & 6 & $60 \%$ \\
\hline & 非常不合适 & 3 & $30 \%$ \\
\hline & 没考虑过此问题 & 0 & 0 \\
\hline \multirow{4}{*}{$\begin{array}{c}\text { 少数民族地区是否有必 } \\
\text { 要开发校本课程 }\end{array}$} & 十分有必要 & 4 & $40 \%$ \\
\hline & 有一定的必要 & 4 & $40 \%$ \\
\hline & 没有必要 & 2 & $20 \%$ \\
\hline & 没考虑过此问题 & 0 & 0 \\
\hline \multirow{4}{*}{$\begin{array}{c}\text { 开发校本课程需要哪些 } \\
\text { 方面的支持 }\end{array}$} & 学校及领导 & 10 & $100 \%$ \\
\hline & 社会及有关部门 & 10 & $100 \%$ \\
\hline & 学生 & 10 & $100 \%$ \\
\hline & 家长 & 9 & $90 \%$ \\
\hline
\end{tabular}

\section{3. 2 课程开发意识和能力淡薄}

我国长期存在着 “重教育轻课程” 的现象, 无论教师的职前教育还是 职后教育都缺少课程知识培训。对于职前教育, 目前的师范生培养更注重 的是专业知识的内化, 与课程开发相关的师范生课程几乎没有, 不利于教 师的个人课程思想形成。入职后教育培训的关注点主要集中在加强教师的 专业技能及教育知识技能方面, 以期帮助教师更快的接受最新的教育方法 及理念, 但关于课程开发方面的培训相比来看少很多。教师的课程开发意 识淡薄成为校本课程开发的难点问题。

\subsection{3 升学压力与课程负担过大}

在大力倡导核心素养教育的背景下, 仍有很多学校片面追求升学率, 以成绩看学生, 升学率看学校的 “应试教育” 现象愈演愈烈。过度追求升 学率必然会导致课程方案在执行过程中被扭曲, 压缩校本课程的时间用于 开设必修课, 甚至体育课和选修课的时间被取消, 这就造成了国家课程和 校本课程的“冲突”, 致使校本课程的开发受到阻碍。

\section{2 开发流程}

乌海市R中学化学校本课程开发的流程分为以下几步:

(1)成立专门的课程开发小组, 收集信息。一方面对学校有关教学的相 关因素进行分析整合, 评估教师及学生的现有情况, 进而也了解目前影响 教学的外部因素, 总结当前教学状态的优缺点; 另一方面以蒙古族传统文 化为背景, 了解学生对于化学学科目前的学习状态及学习需求。

(2)综合考虑现有情况确立校本课程开发的目标和理念, 明确总的指导
思想和基本原则, 充分体现个性与共性, 细化课程规划, 使校本课程达到作 用最大化, 弥补少数民族地区国家课程难以涉及的不足。

(3)制定校本课程开发指南, 进行课程开发。这一步十分重要, 首先要明 确课程开发的主题, 进而编制校本课程所需的教材等相关材料, 并且确保 教材的可行性及实效性等。

(4)实施校本课程并进行评价。根据课程内容及要求确定实施方式、时 间、地点、参与人员等因素, 并且在实施过程中根据具体情况及时调整, 同时做好课程参与人员及课程本身的评价工作。

\section{3 高中化学校本课程开发案例研究}

3.1案例一: 身边的化学一饮食中的化学知识

开发背景: 蒙古族地区化学类相关的专著较少, 但很多因素与化学 息息相关, 如饮食、服饰等 ${ }^{[3-4]}$ 。在蒙古族传统文化的背景下, 充分挖掘 与化学相关的课程资源, 展示蒙古族地区特有的化学文化, 促进不同民 族文化间的思想碰撞。以新课标为基础分析蒙古族地区现状, 找出现行 化学教材中对文化地域差异的忽略之处, 找出与蒙古族学生生活情境或 认知意识不一致或不熟知的内容, 以此作为校本课程开发的内容开发校 本课程。

课程框架: 以蒙古族文化为背景, 整理蒙古族文化中的化学知识, 如牛 奶的丁达尔现象, 配饰的材质、蒙古包发电等等。

课程目标: 让学生体验生活中的化学, 更好的理解所学知识, 同时提高 学生的积极性。

个案：饮食文化中的化学知识。

每个蒙古族人对牛奶都不陌生, 牛奶是呈乳白色的不透明液体, 也是 一种复杂的胶体混合物。化学课程胶体的讲授用的是氢氧化铁, 但对于学 生来说是陌生的, 而且氢氧化铁胶体的制备过程复杂, 课堂演示浪费时间, 需控制氯化铁的滴加量, 为防止胶体又需准确把握加热时间, 因此改用牛 奶验证胶体的丁达尔现象。

原料选择原因：蒙古族学生熟知，操作简便容易调控，节约时间。

器材及原料: 激光笔, 烧杯, 牛奶。

实验步骤:

(1)取两个小烧杯, 分别加入 $25 \mathrm{~m} 1$ 的稀释牛奶和氯化钠溶液。

(2)将烧杯置于阴暗处, 用激光笔照射烧杯中液体, 观察现象。

3.2 案例二：化学应用一立足蒙古族地区的化学建模

课程开发背景: 化学建模是指用化学语言描述实际现象的过程。以化 学建模为切入点, 让学生从熟悉的环境中发现化学, 更好的理解和应用化 学知识。蒙古族中学应充分考虑学生的实际生活情况及教育基础情况, 对 化学教材中的典型性应用知识创设恰当情境, 开展化学建模, 提高学生运 用化学知识解决实际问题的能力。

课程框架: 以马奶酒的制作方法为切入点, 与蒸馏实验相对比, 开展化 学建模。

课程目标: 培养学生化学的应用意识和能力, 提高学生综合运用化学 各部分知识以及化学与现实生活的联系能力, 为学生发展奠定基础。

个案: 马奶酒具有蒙古族特色的饮品, 其制作方法有两种, 原始方法是 将新鲜的马奶倒入特制的囊中放在马背上, 在日常游牧的过程中马奶会撞 击发热, 慢慢发酵, 当里面的马奶腥味消失, 变成无色而透明的液体, 奶酒 就制成了, 这种方法简单但制得酒的度数不高, 现在一般选用如图 2 的制作 方法, 将发酵好的奶倒入锅中加热, 奶锅上方依次放筒状罩和冷水装置, 从 桶内伸出一根导管并通入外部容器中, 蒸馏出来的液体即为奶酒, 这样制 得的奶酒度数可达 48 度。酿制奶酒的装置虽然和实验室的蒸馏装置 (如图 3) 不完全相同 ${ }^{[5]}$, 但原理相同, 充分体现了民族智慧。 


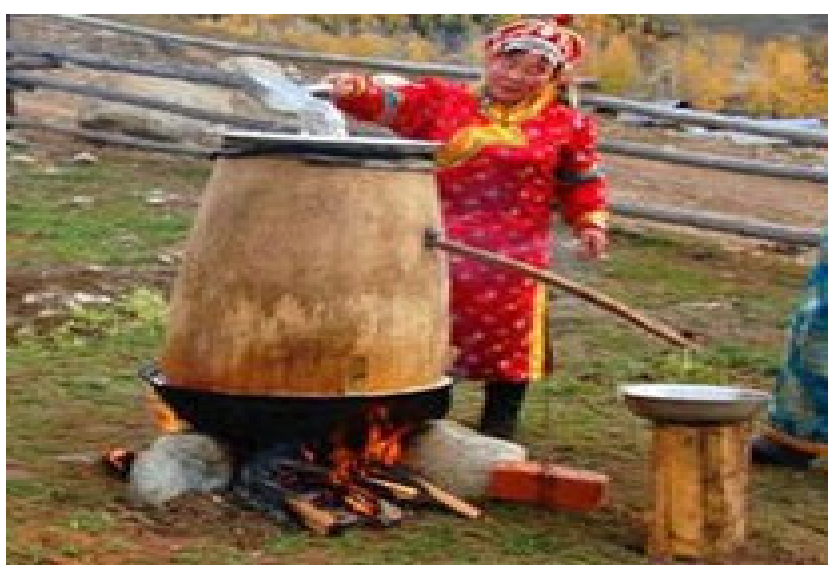

图2 制作马奶酒

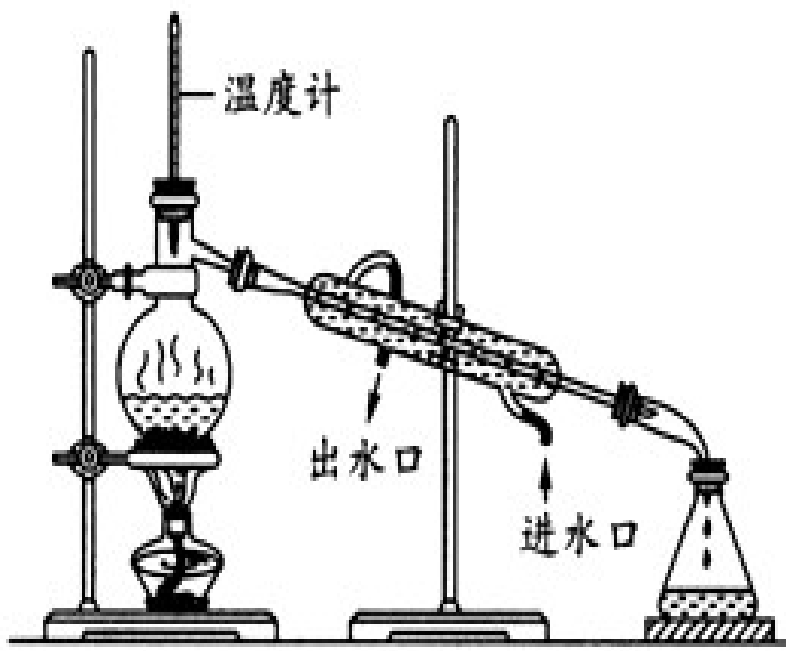

图3 蒸馏

建模分析：马奶酒的制作原理与蒸馏相同, 对比找出二者作用相同的 器材并描述作用, 并指出要想更高效的制作马奶酒需要在那些部位有所提
升。这一建模难度中等, 马奶酒的制作过程源于生活, 学生熟悉并且感兴趣, 当枯燥的课本内容可以与日常生活联系起来的时候, 更能激发学生的学习 热情及对知识的自主探索欲望, 为其将来的发展奠定坚实的基础。

\section{4 结论}

选择内蒙古民族地区中学化学校本课程开发这个课题, 缘于本人对民 族地区化学教育的关注。对本次研究进行总结, 即使三级课程管理的体制 在我国已经确立多年, 但内蒙古民族地区的校本课程开发意识仍较为淡薄, 本文对内蒙古自治区乌海市R中学的化学校本课程开发状况进行分析, 以 期开发具有民族特色的化学校本课程, 本次研究具有一定的典型性和普适 性。蒙古族地区校本课程的开发应更多的参考现有的课程开发案例, 并结 合自身区域特色, 发挥自身优势, 以特色性校本课程为机遇构建属于内蒙 古民族地区的教育生态, 为蒙古族学生开创更贴近生活的学习教材, 提供 轻松高效的学习课程, 为学生的未来发展打下坚实的基础。内蒙古民族地 区中学化学校本课程的开发不仅有利于蒙古族学生的学习, 促进学生更好 的适应国家课程, 提高自身的学业成就, 同时也对我国的民族课程教育做 了重要的完善, 促进了对民族地区的基础教育, 也为其他地区少数民族学 校的校本课程开发提供范本, 同时也希望有更多的教育学者参与到少数民 族地区的学科性校本课程开发的相关研究中来。

[参考文献]

[1]宝日乐.内蒙古地方课程开发与实施的理论探讨 [D]. 呼和浩特: 内 蒙古师范大学,2004,(04):69.

[2]中华人民共和国教育部.普通高中化学课程标准(2017 年版)[S].北 京:人民教育出版社,2017:2-7.

[3]卢九涁. 蒙古族服饰的形成与发展 [J].内蒙古师范大学学报(哲学社 会科学版),2007,(S1):646-647.

[4]薛志刚.浅析蒙古族的饮食文化 [J]. 南宁职业技术学院学 报,2019,14(3):6-7.

[5]宋新琦.普通高中课程标准实验教科书・化学选修 5[M].北京: 人民 教育出版社,2004:13.

\section{选题项目:}

内蒙古师范大学2018年 “内蒙古民族地区校本课程开发研究” 课 题(项目编号：CXJJS18085)。 